\title{
Synergistic effect of natural zeolites on flame retardant additives
}

\author{
H. Demir, E. Arkış, D. Balköse*, S. Ülkü \\ Izmir Institute of Technology, Faculty of Engineering, Department of Chemical Engineering, Gülbahçe Campus, \\ 35430 Urla Izmir, Turkey
}

Received 2 November 2004; received in revised form 30 December 2004; accepted 18 January 2005

Available online 23 March 2005

\begin{abstract}
The thermal degradation and flammability of intumescent fire-retardant polypropylene matrix composites consisting of ammonium polyphosphate (APP) as an acid source and blowing agent, pentaerythritol (PER) as a carbonisation agent and natural zeolite (clinoptilolite rich, Gördes II) as a synergistic agent were examined. APP and PER combinations were examined at different ratios $(0.25,0.33,0.5,1,2,3$, and 4$)$ for optimisation of the formulation for flame retardancy. The zeolite was incorporated into flame retardant formulation at four different concentrations $(1,2,5$, and $10 \mathrm{wt} \%)$ to investigate the synergism between the flame retardant materials. The thermal degradation and flammability of composites were characterized by thermogravimetric analysis (TGA) and by limiting oxygen index (LOI) measurement and horizontal burning (HB) tests. A synergistic effect in flame retardancy was observed when natural zeolites were used in combination with APP and PER.
\end{abstract}

(C) 2005 Elsevier Ltd. All rights reserved.

Keywords: Natural zeolite; Intumescence; Flame-retardant polypropylene

\section{Introduction}

The research and developments on new engineering materials belong to the important fields of material science. One can see the continuous competition between the traditional inorganic engineering materials and polymers. Since polymeric materials (including composites) are promising, due to their economic versatile applicability, they are widely used in many applications, such as housing materials, transport and electrical engineering [1-4]. These commercial polymers are easily flammable. Due to increasing demand for polymers, the development of safe and environmental flame retarded polymers is of great importance. Flame retardants are defined as chemical compounds that modify pyrolysis reactions of polymers or oxidation reactions implied in

\footnotetext{
* Corresponding author. Tel.: +9023275062 70; fax: +90232750 6196.

E-mail address: devrimbalkose@iyte.edu.tr (D. Balköse).
}

the combustion by slowing down or by inhibiting them [5]. The flame retardant can act in various ways i.e. physically or chemically. Many types of flame retardants are used in consumer products [6-8]. They are mainly phosphorus, antimony, aluminium and boron-containing compounds, chlorides and bromides [5].

In recent years, intumescent technology has found a place in polymer science as a method of providing flame retardance to polymeric materials. On heating, fire-retardant intumescent material restricts the action of the heat flux or flame. The proposed mechanism is based on charred layer acting as physical barrier, which slows down heat and mass transfer between the gas and the condensed phases [4]. The flame retardant can cause a charred layer of carbon to form on the polymer surface. This can occur, for example, through the dehydrating action of the flame retardant generating double bonds in the polymer. These form the carbonaceous layer by cyclisation and cross-linking. Combinations of flame retardants may produce a synergistic effect of great importance for practical use. 
The fire-retardant properties of polyethylene materials are investigated after incorporating $30 \%$ of flame retardant additives (APP and PER) in the polymer. The system consisted APP/PER mixture for the ratio APP/ PER ratio of $3(\mathrm{wt} / \mathrm{wt})$. The flame retardant polypropylene leads to a limiting oxygen index (LOI) of $32 \%$ indicating maximum flame retardance performance for APP/PER ratio of 3 [9-12]. The addition of zeolites to thermoplastic polymers with combination ammonium polyphosphate and pentaerythritol, leads to significant improvement of their fire-retardant performance. Bourbigot et al. [13], carried out flame retardant polymeric matrix composite formulation which consists of APP:PER (3:1) + LRAM3,5 (polyethylene copolymer) and synthetic zeolite. They improved the LOI values of LRAM3,5 from 18 to $40 \%$ and $38.8 \%$ by using APP:PER (3:1) 1.5\% Y and 4A types of synthetic zeolites, respectively. The comparison of several zeolites used in intumescent formulations has shown that there is no relation between the type of exchangeable cation or the hole size of the zeolites and FR performances. Thermogravimetric analysis revealed that the zeolite may act as a catalyst for development of the intumescent carbonaceous material and stabilise that carbonaceous residue resulting to the degradation of the intumescent shield [13].

In this study, the goal was to increase the flame resistance of polypropylene and to investigate influence of natural zeolites on flame retardant additives. For this purpose, an intumescent flame retardant system was selected. Ammonium polyphosphate (APP) was used as acid source and blowing agents and pentaerythritol (PER) was used as carbonisation compound in the intumescent system. Natural zeolite, clinoptilolite, was used for its synergism with intumescent flame retardant materials. For best flame retardant performance, optimum APP/PER ratio and zeolite loading were investigated. Flammability of samples was characterized with horizontal burning test (HB), limiting oxygen index (LOI), and thermogravimetric analysis (TGA).

\section{Experimental}

\subsection{Materials}

Gördes zeolitic tuff having particle size below $50 \mu \mathrm{m}$ and supplied by Enli Madencilik Company was used in this study. It was found, by a previous study of Top and Ülkü [14], to contain $80 \mathrm{wt} \%$ of clinoptilolite. In addition to zeolitic phase, quartz, cristobalite, and $\mathrm{K}$-feldspar were detected in its X-ray diffraction diagram [14]. It contained $66.36 \% \mathrm{SiO}_{2}, 11.36 \% \mathrm{Al}_{2} \mathrm{O}_{3}$, $1.23 \% \mathrm{Fe}_{2} \mathrm{O}_{3}, 3.84 \% \mathrm{~K}_{2} \mathrm{O}, 0.99 \% \mathrm{Na}_{2} \mathrm{O}, 2.34 \% \mathrm{CaO}$, $0.42 \% \mathrm{MgO}$ and $14.22 \% \mathrm{H}_{2} \mathrm{O}$ [14].
Exolit 422 ammonium polyphosphate (APP) $(n>$ 1000), having soluble fraction in water below $1 \%$, and average particle size of $15 \mu \mathrm{m}$ supplied by Clariant, pentaerythritol (PER), having particle size below $75 \mu \mathrm{m}$ supplied by MKS Marmara Kimya Sanayi A.Ş., polypropylene (PP) MH 418, supplied by PETKIM A.Ş. and antioxidant, butylated hydroxy toluene, supplied by Sigma Co. were used in the experiments.

\subsection{Compounding}

Polypropylene matrix composites were prepared by blending of PP pellets, flame retardant materials (APP and PER), natural zeolite clinoptilolite and antioxidant $(0.5 \%)$ by using a Haake polydrive mixer. Concentration of fillers was fixed at 30\% mass of total amounts of composite. Amounts of APP were changed in proportion to amounts of pentaerythritol $(4,3,2,1,0.5,0.33$, and 0.25 ratios). Zeolite dried at $120{ }^{\circ} \mathrm{C}$ was added with mass fractions of 1,2, 5 and $10 \%$. Clinoptilolite and APP were dried in an oven at $120^{\circ} \mathrm{C}$ for over night. Samples were mixed at 60 revolutions per minute screw speed at $190{ }^{\circ} \mathrm{C}$ for $10 \mathrm{~min}$. At first, polypropylene was melted at $190{ }^{\circ} \mathrm{C}$ in the plastograph for $2 \mathrm{~min}$. and then antioxidant $(0.5 \mathrm{wt} \%)$ was added to the molten PP. Afterwards, clinoptilolite, APP and PER were added. Mixed materials were pressed by Carver hot press at $190{ }^{\circ} \mathrm{C}$ and 100 bar, into sheets having dimensions of $15 \times 15 \times 0.3 \mathrm{~cm}$. Composites were cut by bar shaped hollow die punch, with dimensions of $125 \times 12.5 \times 3 \mathrm{~mm}$ for UL-94 test and $125 \times 6.5 \times 3 \mathrm{~mm}$ for LOI test.

\subsection{Flammability tests}

Horizontal test method for rate of burning and extent and time of burning of self-supporting plastics in a horizontal position was constructed according to ASTM D 5020 and ASTM D 635 [15,16]. Average burning rate is reported as the average of the burning rates of all specimens which have burned to the mark in $\mathrm{cm} / \mathrm{min}$. Average time of burning (ATB) and average extent of burning (AEB) were calculated according to Eqs. (1) and (2), respectively.

$\mathrm{ATB}=\sum(t-30 \mathrm{~s}) /$ number of specimens

$$
\operatorname{AEB}(\mathrm{mm})=\sum_{\text {number of specimens }}(100 \mathrm{~mm}-\text { unburned length }) /
$$

The limiting oxygen index (LOI) test method for measuring the minimum oxygen concentration to support candle-like combustion of composites was determined according to ASTM D 2863 [17]. The minimum concentration of oxygen in a mixture of oxygen and nitrogen flowing upward in a test column that supported 
combustion was measured under equilibrium conditions of candle-like burning. The gas flow rate in the column was adjusted by a Cole Parmer flowmeter (A-3227-30) to $4 \pm 1 \mathrm{~cm} / \mathrm{s}$.

\subsection{Thermal analysis}

TGA of composites was carried out using a SETERAM Thermal Gravimetric Analyser from room temperature to $600{ }^{\circ} \mathrm{C}$ at a heating rate of $10{ }^{\circ} \mathrm{C} / \mathrm{min}$. Nitrogen was used as a carrier gas with a constant flow rate during analysis.

\subsection{Scanning electron microscopy (SEM)}

Scanning electron microscopy (SEM) was used to examine the morphology of the cross-section of burnt and non-burnt FR-PP composites by using a Philips XL-305 FEG - SEM.

\section{Results and discussion}

\subsection{Flammability tests}

Horizontal burning test results, burning time, length and rate of composites in air are illustrated in Table 1. While most of the composites did not burn in atmospheric conditions, some of them either completely or partially burned. This indicates that, some composites extinguished themselves in the atmosphere. Burning time and length must be taken into account when burning rates of all composites were compared with each other. None of the composites having high APP/PER $(1,2,3$ and 4$)$ ratio burnt in air. Composites having low zeolite content $(1,2,5 \%)$ except the ones having low APP:PER (1:3 and 1:4) ratio also did not burn in horizontal burning tests. It was observed that the addition of zeolite to PP matrix, decreased the flammability resistance of $\mathrm{PP}$, on the other hand addition of flame retardant materials increased the flammability resistance of PP. However, their horizontal burning rates were lower than that of pure PP. Burning rates of pure PP, APP:PER (1:4) and APP:PER (1:4) + 1\% zeolite were $0.39,0.34$ and $0.28 \mathrm{~mm} / \mathrm{s}$, respectively. Composites having 10\% zeolite and APP:PER ratio greater than 1 had generally higher burning rates (between 0.38 and $0.51 \mathrm{~mm} / \mathrm{s}$ ) than pure PP (0.39). Samples with low APP:PER ratio $(1: 4,1: 3)$ and $10 \%$ zeolite burning was complete but with a slower rate $(0.33-0.35 \mathrm{~mm} / \mathrm{s})$ than pure PP. Results indicated that, flame retardant materials and low level zeolite addition enhanced flammability resistance of polymer. HB tests were not sufficient to show the synergism of flame retardants and zeolites thus limiting oxygen index of the samples were measured.
Table 1

UL-94 tests data for not-burnt flame retardant PP composites

\begin{tabular}{|c|c|c|c|}
\hline Flame retardant composite & $\begin{array}{l}\text { Burning } \\
\text { rate }(\mathrm{mm} / \mathrm{s})\end{array}$ & $\begin{array}{l}\text { Burning } \\
\text { length (mm) }\end{array}$ & $\begin{array}{l}\text { Burning } \\
\text { time (s) }\end{array}$ \\
\hline Pure PP & 0.39 & 100 & 259 \\
\hline APP:PER (1:4) + PP & 0.34 & 51.4 & 151 \\
\hline APP:PER (1:3) + PP & 0.1 & 18.2 & 179 \\
\hline $\begin{array}{l}\text { APP:PER (1:4) + 1\% } \\
\text { Zeolite + PP }\end{array}$ & 0.28 & 100 & 358 \\
\hline $\begin{array}{l}\text { APP:PER (1:3) + 1\% } \\
\text { Zeolite + PP }\end{array}$ & 0.37 & 41.6 & 113 \\
\hline $\begin{array}{l}\text { APP:PER (1:4) + 2\% } \\
\text { Zeolite + PP }\end{array}$ & 0.31 & 100 & 323 \\
\hline $\begin{array}{l}\text { APP:PER (1:3) + 2\% } \\
\text { Zeolite + PP }\end{array}$ & 0.46 & 47 & 102 \\
\hline $\begin{array}{l}\text { APP:PER (1:4) + 5\% } \\
\text { Zeolite + PP }\end{array}$ & 0.37 & 100 & 271 \\
\hline $\begin{array}{l}\text { APP:PER (1:3) + 5\% } \\
\text { Zeolite + PP }\end{array}$ & 0.29 & 100 & 342 \\
\hline $\begin{array}{l}\text { APP:PER }(1: 2)+5 \% \\
\text { Zeolite + PP }\end{array}$ & 0.36 & 82 & 229 \\
\hline $\begin{array}{l}\text { APP:PER (1:4) + 10\% } \\
\text { Zeolite + PP }\end{array}$ & 0.35 & 100 & 288 \\
\hline $\begin{array}{l}\text { APP:PER (1:3) + 10\% } \\
\text { Zeolite + PP }\end{array}$ & 0.33 & 100 & 306 \\
\hline $\begin{array}{l}\text { APP:PER (1:2) + 10\% } \\
\text { Zeolite + PP }\end{array}$ & 0.30 & 81.4 & 271 \\
\hline $\begin{array}{l}\text { APP:PER (1:1) + 10\% } \\
\text { Zeolite + PP }\end{array}$ & 0.49 & 43.8 & 89 \\
\hline $\begin{array}{l}\text { APP:PER }(2: 1)+10 \% \\
\text { Zeolite + PP }\end{array}$ & 0.51 & 15.6 & 31 \\
\hline $\begin{array}{l}\text { APP:PER }(3: 1)+10 \% \\
\text { Zeolite + PP }\end{array}$ & 0.38 & 26.2 & 69 \\
\hline $\begin{array}{l}\text { APP:PER (4:1) + 10\% } \\
\text { Zeolite + PP }\end{array}$ & 0.51 & 35.8 & 71 \\
\hline
\end{tabular}

Fig. 1 shows the effects of flame retardant materials and zeolite on flammability of PP separately. In order to research synergism, each material's effect on flammability of PP should be known. The LOI value $(19 \%)$ was unchanged with addition of 30\% APP into polypropylene. Carbonisation agent (PER) addition alone was not sufficient for providing char formation which was important for intumescent system since it decreased LOI value of PP to $17 \%$.

Composites with zeolite also had lower LOI values than that of pure PP. An increase in zeolite concentration in composite formulations leads to decrease in LOI up to $16 \%$. Fig. 2 illustrates the LOI values of flame retardant polypropylene composites versus APP:PER ratios with different zeolite content. The LOI value of PP rose from 19 to $32 \%$ with flame retardant APP and PER addition at 1:1 ratio. The LOI value of composites with 3:1 APP and PER ratio was found to be very close to that found by previous investigators [9-12]. Results indicated that the APP had important role in intumescent flame retardant system. An increment in the APP amount, increased LOI values of composites. 


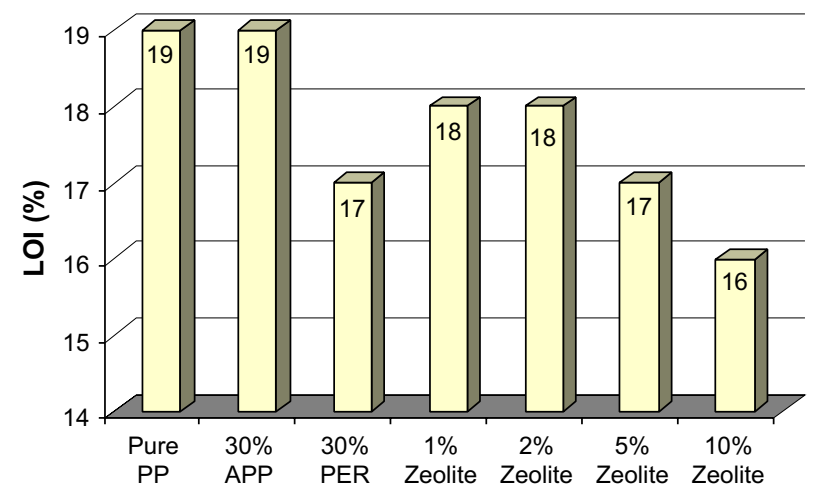

Fig. 1. Limiting oxygen index of PP, $30 \mathrm{wt} \%$ APP + PP, $30 \mathrm{wt} \%$ PER + PP, and different zeolite loading in PP.

For high levels ratio of APP:PER (4:1), the LOI decreased significantly lower than that of the other APP/PER ratios, which indicated there was an optimum concentration of APP. Combination of APP, PER and low level zeolite gave better results than each one added to PP separately. At low zeolite loading $(1,2,5 \mathrm{wt} \%)$, the LOI values of composites were higher than that of without zeolite formulation. Synergism between zeolite and flame retardant additives can be easily observed at low zeolite loading. Synergistic effect was observed in APP:PER (3:1) and (2:1) PP formulations having 2 and $5 \%$ zeolite loadings respectively. Two percent zeolite addition in APP:PER (3:1) PP composite increases the LOI values from 32 to $37 \%$. While the LOI of APP:PER (2:1) PP composite was $31 \%$, it was composite with $5 \mathrm{wt} \%$ of zeolite and APP:PER (2:1) was $38 \%$ being the maximum LOI value among all flame retardant polypropylene composites. Zeolites act as a catalyst for the development of the intumescent carbonaceous material and stabilise the carbonaceous residue resulting from degradation of the intumescent shield [3]. When zeolite loading increased to $10 \%$, limiting oxygen index values decreased dramatically. At $10 \%$ zeolite content, the LOI value decreased below $21 \%$ of oxygen concentration. It indicated that $10 \%$ zeolite content flame retardant PP composites, having APP:PER less than 1:2, could burn

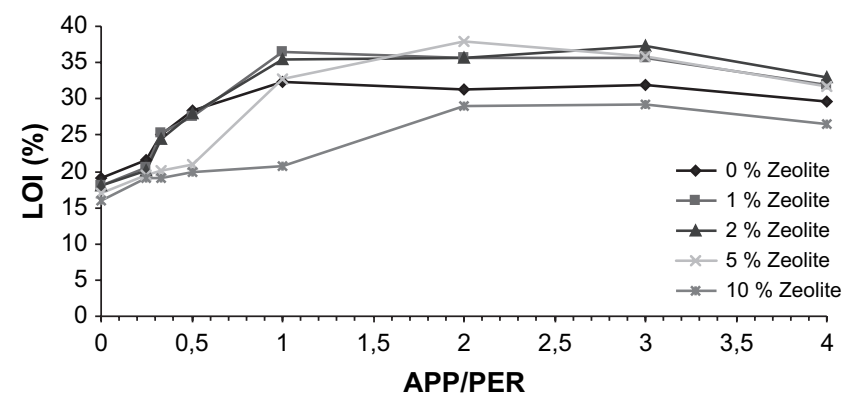

Fig. 2. Limiting oxygen index of all flame retardant polypropylene composites versus APP/PER ratio according to zeolite concentration.

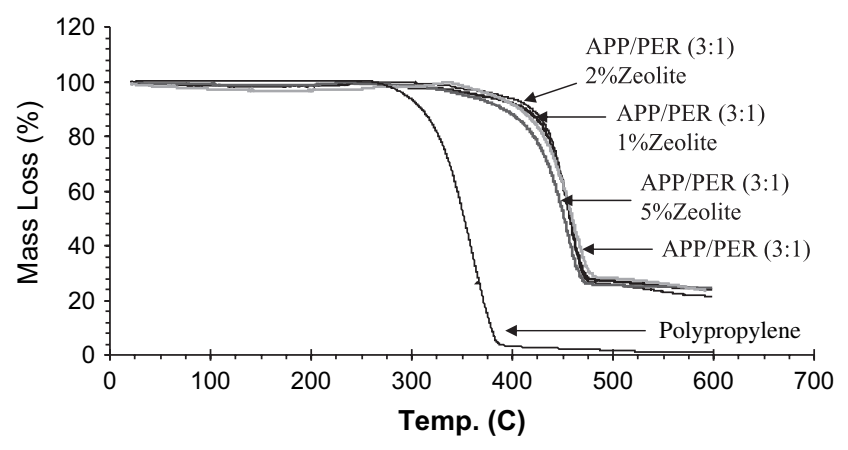

Fig. 3. TGA thermograms of APP/PER (3:1) + PP composites with different zeolite loading.

easily in atmospheric conditions. This was also confirmed by $\mathrm{HB}$ tests, as they had burned in air with burning rates around $0.35 \mathrm{~cm} / \mathrm{s}$.

The LOI of APP:PER $(3: 1)+\mathrm{PP}+2 \%$ natural zeolite and APP:PER (2:1) + PP $+5 \%$ natural zeolite formulations were found to be 37.4 and $38 \%$, respectively. Similar flame retardance performance of APP:PER (3:1) in polyethylene copolymer with either $\mathrm{Y}$ or $4 \mathrm{~A}$ zeolites was also observed by previous studies [13].

\subsection{Thermal analysis}

All composites having intumescent flame retardants started to lose their mass at least $100{ }^{\circ} \mathrm{C}$ higher at $340{ }^{\circ} \mathrm{C}$ than pure PP composites as seen in Fig. 3. Mass loss curves of intumescent composites without and with zeolite almost coincided with each other. The char residues of composites and polypropylene at $600{ }^{\circ} \mathrm{C}$ and maximum mass loss temperature are illustrated in Table 2. Carbonaceous residue was found as 22.7, 23.4, and $24.5 \%$ for APP:PER (1:1) $5 \%$ zeolite, APP:PER

Table 2

Maximum rate mass loss temperature and char residue of composites at $600^{\circ} \mathrm{C}$

\begin{tabular}{lll}
\hline Samples & $\begin{array}{l}\text { Max. rate } \\
\text { of mass loss } \\
\text { temperature }\left({ }^{\circ} \mathrm{C}\right)\end{array}$ & $\begin{array}{l}\text { Residue }(\%) \\
\text { at } 600{ }^{\circ} \mathrm{C}\end{array}$ \\
\hline PP & 369 & 0.9 \\
APP:PER (1:1) & 470 & 18.3 \\
APP:PER (2:1) & 471 & 20.2 \\
APP:PER (3:1) & 466 & 23.4 \\
APP:PER (1:1) 1\% Zeolite & 469 & 21.5 \\
APP:PER (1:1) 2\% Zeolite & 470 & 19.4 \\
APP:PER (1:1) 5\% Zeolite & 461 & 22.7 \\
APP:PER (2:1) 1\% Zeolite & 471 & 22.1 \\
APP:PER (2:1) 2\% Zeolite & 463 & 18.1 \\
APP:PER (2:1) 5\% Zeolite & 471 & 23.4 \\
APP:PER (3:1) 1\% Zeolite & 462 & 23.9 \\
APP:PER (3:1) 2\% Zeolite & 462 & 21.4 \\
APP:PER (3:1) 5\% Zeolite & 457 & 24.5 \\
\hline
\end{tabular}


(2:1) 5\% zeolite, and APP:PER (3:1) 5\% zeolite, respectively. Mass loss percentage of with and without zeolite composites almost were close to each other. Taking that into account, the thermal behaviour of raw materials was investigated in $\mathrm{N}_{2}$ medium in which flame retarded materials do not give oxidation reactions. However, residue of flame retardant composites, having $5 \%$ zeolite, was higher than without zeolite and low zeolite content composites. Maximum rate mass loss temperature changes between 457 and $471{ }^{\circ} \mathrm{C}$ for flame retardant composites and is nearly $100{ }^{\circ} \mathrm{C}$ higher than that of pure PP, $369^{\circ} \mathrm{C}$.

\subsection{Morphology of non-burnt and burnt composites}

Fig. 4 shows SEM micrographs of non-burnt and burnt PP, APP:PER (3:1) + PP composites with and without zeolite. Flame retardant materials (APP and PER) and zeolite particles were well distributed in polypropylene matrix and bubble formation on surface of composites did not occur during their preparation as seen in Fig. 4 $\mathrm{a}$ and $\mathrm{c}$. Hence, bubbles formed in burnt flame retarded composites can be easily seen in Fig. $4 \mathrm{~b}$ and d. Bubbles are distributed randomly and have different size and shapes. The bubble size increased 2 or 3 times with incorporation of zeolite in composites.

\section{Conclusions}

Addition of flame retardant materials to the PP matrix increased flammability resistance of PP. Most of the composites did not burn in atmospheric conditions. APP, PER and clinoptilolite rich zeolite did not improve flame retardancy of polypropylene individually. Results indicated that the APP has important role in combination of flame retardant materials and zeolite. Decreasing in amount of APP reduced LOI values of composites. Synergism between zeolite and flame retardant additives could be easily observed for combination of APP, PER with zeolite in composites. The limiting oxygen index values of pure PP increased from 19 to $31 \%$ with the addition of APP:PER $(2: 1)$ into PP. Also with the addition of $5 \%$ of zeolite into APP:PER $(2: 1)+$ PP formulation, the limiting oxygen index values reach its maximum value of $38 \%$.
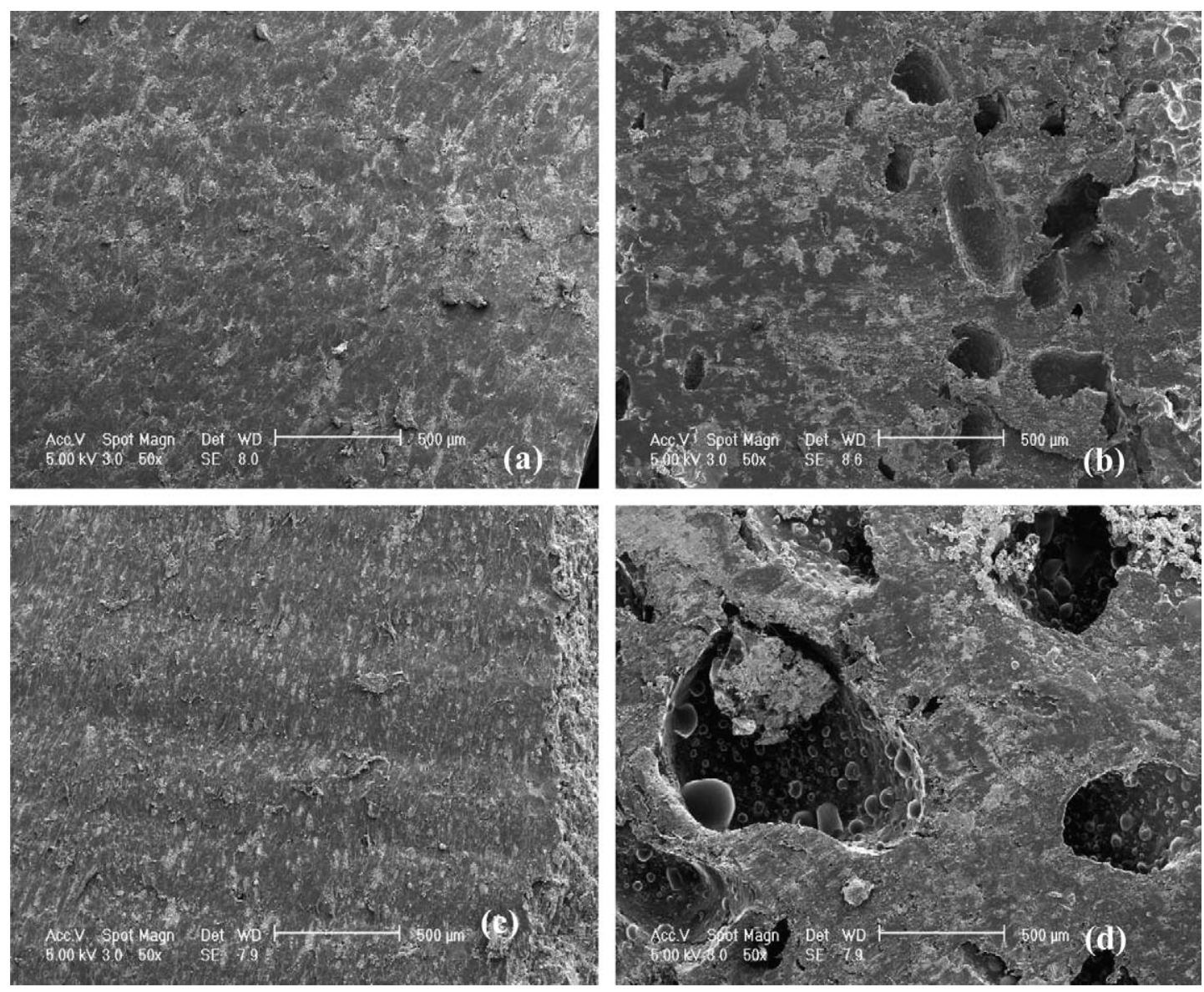

Fig. 4. SEM micrograph of cross-section of $(a, b)$ non-burnt and burnt APP:PER (3:1) + PP composite, (c, d) non-burnt and burnt APP:PER $(3: 1)+1 \%$ Zeolite + PP composite. 
Maximum rate mass loss temperature of flame retardant composites was nearly $100{ }^{\circ} \mathrm{C}$ higher than that of pure PP. Char of FR-PP composites were higher than pure PP $(0.9 \%$ mass $)$. The mass of char residue was found as 18.3, 20.2 and 23.47\% for APP:PER (1:1), APP:PER (2:1) and APP:PER (3:1), respectively.

In SEM microphotographs of cross-section of composites, flame retardant materials (APP and PER) were well distributed in polypropylene matrix and any bubble formation during preparation of composites was not observed. Bubbles, formed in burned composites, were distributed randomly and have different size and shapes. The zeolite addition to composites increased the bubble size 2 or 3 times.

Addition of $2-5 \%$ natural zeolite to APP:PER (2:1 and 3:1) and PP system increased flame retardancy in a similar manner to synthetic zeolites in other polymer systems.

\section{Acknowledgement}

This project has been supported by the research fund of Izmir Institute of Technology (Project No. IYTE-342002).

\section{References}

[1] Almeras X, Le Bras M, Hornsby P, Bourbigot S, Marosi Gy, Keszei S, et al. Effect of fillers on the fire retardancy of intumescent polypropylene compounds. Polymer Degradation and Stability 2003;82(2):317-23.

[2] Anna P, Marosi Gy, Bourbigot S, Le Bras M, Delobel R. Intumescent flame retardant system of modified rheology. Polymer Degradation and Stability 2002;77:243-7.

[3] Bourbigot S, Le Bras M, Breant P, Tremillon JM, Delobel R. Zeolite new synergistic agents for intumescent fire retardant thermoplastic formulations criteria for the choice of the zeolite. Fire and Materials 1996;20(3).

[4] Bourbigot S, Le Bras M, Delobel R, Decressain R, Amourex JP. Synergistic effect of zeolite in an intumescent process study of the carbonaceous structure using solid-state NMR. Faraday Transactions 1996;92(1):149-58.

[5] Seymour RB. Additives for plastic. New York: Academic Press; 1978.

[6] Troitzsch J. International plastics flammability handbook. New York: Hanser Pub; 1990.

[7] Sain M, Park SH, Suhara F, Law S. Flame retardant and mechanical properties of natural fibre-PP composites containing magnesium hydroxide. Polymer Degradation and Stability 2004; 83:363-7.

[8] Zhu S, Shi W. Thermal degradation of a new flame retardant phosphate methacrylate polymer. Polymer Degradation and Stability 2003;80:217-22.

[9] Delobel R, Le Bras M, Ouassou N, Alistiqsa F. Thermal behaviors of ammonium polyphosphate-pentaerythritol intumescent additives in polypropylene formulations. Journal of Fire Sciences 1990;8(2):85

[10] Bourbigot S, Le Bras M, Delobel R. Carbonization mechanisms resulting from intumescence. Association with the ammonium polyphosphate-pentaerythritol fire retardant system. Carbon 1993;31(8):1219.

[11] Delobel R, Bourbigot S, Le Bras M, Schmidt Y, Leroy JM. Invariant values of kinetic parameters. Evaluation of fire retardancy. Application of to the polypropylene-ammonium polyphosphate-pentaerythritol system. Makromolekulare Chemie, Macromolecular Symposia 1993;74:59.

[12] Bourbigot S, Delobel R, Le Bras M, Normand D. Comparative study of the integral TG methods used in the invariant kinetic parameters method. Application to the fire-retardant polypropylene. Journal de Chimie Physique et de Physico-Chime Biologique 1993;90:1909.

[13] Bourbigot S, Le Bras M, Delobel R, Decressain R, Amourex JP. 4A Zeolite synergistic agent in new flame retardant intumescent formulation of polyethylenic polymers-study of the effect of the constituent monomers. Polymer Degradation and Stability 1996;54:275-87.

[14] Top A, Ülkü S. Silver zinc, and copper exchange in a Naclinoptilolite and resulting effect on antibacterial activity. Applied Clay Science 2004;27:13-9.

[15] ASTM D 5025-91. Standard specification for a laboratory burner used for small-scale burning tests on plastic materials; 1991. [09.02].

[16] ASTM D 635-91. Standard Test Method for rate of burning and/or extent and time of burning of self supporting plastics in a horizontal position; 1991. [08.03].

[17] ASTM D 2863-91. Standard Test Method of measuring the minimum oxygen concentration to support candle-like combustion of plastics (oxygen index); 1991. [08.04]. 